Strydom $H$

\title{
A PARTICIPATORY ACTION RESEARCH APPROACH TO AGEING IN A PARTICULAR COMMUNITY IN THE NORTH-WEST PROVINCE OF SOUTH AFRICA
}

\author{
Prof H Strydom, School for Psycho-social Behavioural Sciences: Division Social Work, \\ Potchefstroom University for Christian Higher Education, Potchefstroom
}

\section{INTRODUCTION}

In the Participatory Action Research model (the PAR model) research and action to solve a particular problem in a specific community take place simultaneously (Schurink, 1998:405418; Strydom, 2001:379-392). The PAR model aims at combining research with direct service delivery for the benefit of the community. Health scientists, and specifically psychosocial behavioural scientists, encounter a philosophical dilemma in the sense that they have to do research according to the requirements of the first world, but in the same time they have to adhere to the requirements of developing countries. In developing countries terminology such as cost effectiveness, utility, limited funds, capacity building, developmental approach, the speedy solution to problems and positive short-term reaction is important in research (White Paper on Social Welfare, 1997).

Participatory action research can be seen as the health sciences' response to and acknowledgement of their involvement with social justice - this model can enhance change from local action to full-scale social change (Healy, 2001:93). It reports on the unfolding of one section of the social work profession's response to the Farm Dwellers project. This article is limited to the ageing people on these particular farms and especially their ageing status, advanced ageing and future perspective.

\section{BACKGROUND TO THE STUDY}

The Transition, Health and Urbanisation in South Africa (THUSA) study was carried out between 1996 and 1999 in the North-West Province of South Africa to document the effect of urbanisation on the general health status of the African population. The THUSA study identified farm dwellers as an extremely vulnerable group regarding their low nutritional status, physical and mental health (Vorster et al., 2000). Africans living on farms, rural areas and squatter camps were also compromised with respect to a large number of quality of life indicators.

Agriculture in South Africa is currently undergoing major difficulties and changes. In order to give researchers an overview and understanding of the dynamics involved in agriculture, a workshop was organised in collaboration with all the researchers and the various NGOs involved in agriculture in South Africa. Data from the THUSA study and the outcome of the workshop gave a holistic view of the general problems and dynamics of farmers, farm workers and their families. It was evident that all the dimensions of poverty, such as politics, socioeconomic circumstances, physical and mental health should be addressed by the study.

Researchers from various disciplines, such as Nutrition, Physiology, Psychology, Human Movement Science and Social Work were involved in the first stage of the Farm Labour, Agriculture and General Health study (FLAGH). A proper needs assessment was done on some farms in the North-West Province during December 2001. Each of the disciplines involved in 
the needs assessment made their findings known to the others by way of another report-back workshop in February 2002.

Social work data were collected on various topics such as alcohol consumption, recreational and religious activities, teenage pregnancy and ageing. This article reports only on a section of the social work response to the farm dwellers' situation, namely ageing, advanced age and future perspectives. From the results of the needs assessment, it was evident that certain preventative and therapeutic programmes with sustainable intervention in mind were needed on farms. These programmes should be developed, implemented and evaluated by way of the PAR model in order to establish sustainable intervention programmes on farms.

\section{THE OBJECTIVES OF THE STUDY}

The objectives for this particular section of the FLAGH study can be delineated as follows:

- $\quad$ To carry out a needs assessment on ageing, advanced age and future perspectives of farm workers and their families in the North West Province;

- $\quad$ To develop an appropriate intervention programme to alleviate all the concomitant factors associated with the topic;

- To implement the particular intervention programme;

- To evaluate the intervention and to redesign if necessary;

- To create a continuous intervention - meaning service delivery and support - in which students in Social Work can be trained and be driven by volunteers from the farm community itself.

For the purposes of this particular article only the first two objectives will be considered, in other words the needs assessment and developing the intervention programme.

\section{DEFINITION OF TERMINOLOGY}

Health scientists have to react to the many questions that they are confronted with in their daily practice in the widest sense of the word "health" in the fast-changing circumstances of South African society (Collins, 1999:2; DePoy, Hartman \& Haslett, 1999:560; Van Rooyen, 1998:79). Boersema and Maconachie (1995:6) and Schurink (1998:408) add that the PAR model enhances the development of active involvement, critical thought and social consciousness in the community. In this way disadvantaged communities can optimally utilise the available resources, enhance their social functioning and quality of life and eventually change the social structure in which they function (Babbie, 2001:288). The following specific terms are important in the PAR model and should receive further consideration, namely community, mobilisation, capacity building, empowerment, human well-being, self-reliance and community participation.

In the context of the PAR model the community can be seen as the local community, inhabiting a relatively small area or, a neighbourhood or as a community of interest. In a community like this people are thoroughly aware of each other and interaction takes place on an individual, familial and community level. In this manner common strengths and weaknesses are recognised and the community are enabled to establish informal support systems in collaboration with professional persons. 
The economic welfare and emotional stimulation of communities are becoming increasingly important, seeing that enforced mobilisation and emotional oppression can easily replace disciplined change (Rahman, 1993:18). The model focuses on the involvement and mobilisation of all the participants in the total process of creating a common objective and eventually solving the problem (Rahman, 1993:17; Van Rooyen, 1998:79).

Capacity building refers to the potential, capacity and support of the community in developing skills on various levels in order to become the masters of their own developmental endeavours and to sustain and manage the changes. The total process should be a learning experience for the community and be characterised by flexibility and sustainability within a total capacitybuilding approach (Marais, Muthien, Jansen van Rensburg, Maaga, De Wet \& Coetzee, 2001:325, 404).

Empowerment is the process through which personal, interpersonal, socio-economic and political powers are gained in order that the community itself can change their circumstances and become self-determining researchers (Babbie, 2001:288; Barker, 1995:120; Gibbs, 2001:687; Rothman , 1995:205). Nantel (2001:1) emphasises the following point: “...more successful and more sustainable ... outcomes can be obtained if the community can be empowered to identify their own problems and to identify solutions and implement them through co-operative efforts and the mobilisation of local resources." Participatory action research thus empowers the community with research capabilities in order to move from mere participation to becoming investigators (DePoy, Hartman \& Haslett, 1999:560; Holman, 1987:680; Nantel, 2001:1; Pottier, 1993:1). McNicoll (1999:52) elaborates on this point: "Participatory action research puts research capabilities in the hands of the deprived and disenfranchised people so they can transform their lives for themselves."

Human well-being or welfare can be regarded as the efforts made by a community in order to obtain a condition of overall physical health, emotional comfort and economic security (Barker, 1995:406). The welfare of the community should form the core aim of the total endeavour and should include welfare on all levels, including the social, psychological, physiological, economical, technological, political, cultural and spiritual (Kondrat \& Juliá, 1997:37).

Self-reliance of the community also forms part of the PAR model. Rahman (1993:20-21) emphasises the cultivation of self-reliance and empowerment in the community. Self-reliance is the driving force towards activity that makes the community aware of their own creative abilities, which create confidence in the possibility to solve problems, the courage to accept challenges and the stamina to complete tasks. The overriding aim of the PAR model is to empower the community to help themselves in a self-reliant manner to overcome the problems in their community (Beresford \& Evans, 1999:673-674; Whyte, Greenwood \& Lazes, 1989:514).

Community participation aims at creating a democratic system in order that all members of the community become actively involved in accepting responsibility for their own development (Burkey, 1998:56). Terms such as emancipation, liberalisation, partnership, participation, involvement, action, diversity, social consciousness and equality are important in the PAR model (Alvarez \& Gutiérrez, 2001:2; Beresford \& Evans, 1999:673-674; Morse, 1997:283; Whyte et al., 1989:514). The focus is on the involvement and participation of all the role players in the research project. Participation, research and action are thus core issues in this model (Healy, 2001:94; Holman, 1987:680; Rahman, 1993:91). 
The PAR model can thus be defined as an active, participatory, capacity-building, involving, encouraging, mobilising and enabling research procedure in which the total community and the researcher are involved as equal partners. The aims of the PAR model are the collective generation of knowledge, the planning and reaching of common objectives, and the empowerment of people to participate successfully in their own interest. By being involved in this manner, everyone in the community can play a role to solve problems, to achieve their common objectives and to utilise the available resources optimally. In this manner the community's social functioning, self-reliance, quality of life and welfare in the broadest sense of the word can be enhanced.

\section{PROCESS OF PARTICIPATORY ACTION RESEARCH}

Several authors discuss the PAR process. The following delineation of the process is mainly based on the ideas of Bless and Higson-Smith (2000:56-59); Collins (1999:42-43, 108-117); Kahn (1994:2, 11-12, 95); McNicoll (1999:57-58); Morse (1997:285); Schurink (1998:417); Van Rooyen (1998:82-84) and Whyte et al. (1989:535).

\section{Engagement in the community}

The PAR process is based on the principle of self-development in which the community have to organise themselves into action. The community must be empowered to accept accountability for progress in the project and management of the resources. Requests for involvement in a particular community are mostly focused on social workers and other professionals. A researcher might become aware of a problem in a community or the community itself might, by way of their leaders, ask a particular researcher for help to identify and formulate the problem. Ideally the request for an action research project should come from the community itself. Whatever the case may be, contact with the community should be made on ground level in order to gain entry in the correct manner. The THUSA study pointed towards farm dwellers as the most vulnerable group regarding general physical and mental health status. It was therefore decided to focus the FLAGH study on farm dwellers as such.

PAR functions on the assumption that the particular problem had its origin in the community itself. The participants in the project must be in control of the delineation of the problem, the data gathering and the action to follow. The involvement of an external researcher can easily be misjudged. A researcher has the uncertain and time-consuming task of gaining the trust of the community and of procuring their involvement in the inquiry. All individuals from the community should be given the opportunity of providing input on what they think their problems are and what should be done to empower them to undertake further action. A form of representation from the community in the project should already be gained at this stage. Major attempts were made to gain the trust of farmers, farm workers and their families. A lot of mistrust exists and the research team, and specifically the co-ordinator, had to attempt on several occasions to have open discussions on the aims of the study. This was a timeconsuming task.

All ethical aspects of scientific research had to be taken into consideration throughout the study. Informed consent, avoiding misleading the participants and of violating their privacy, and debriefing the participants on completion of the project can be highlighted as of major importance in this project (Babbie, 2001:475; Hakim, 2000:143; Neuman, 2000:229; Yegidis \& Weinbach, 1996:34). Informed consent was gained by phoning farmers for an appointment to discuss the project in person. Several personal interviews took place with every farmer involved before the farm workers and their families were consulted for their permission to 
participate in the project. The full details of the project had to be discussed in great depth in order to ensure that respondents understood the aim of the programme and that there was no misleading of the participants or violation of their privacy.

\section{Problem identification and problem statement}

The PAR model can be seen as applied research seeing that it is focused on practical problem solving. People, and especially marginalised and under-privileged people, have their own agendas regarding what the problems of their communities are and what should be done about them. These personal agendas must be respected at all times without side-tracking the research endeavour. Perhaps the personal aims of respondents can be integrated with the envisaged aims of the researchers. In order to gain an impression of the real problem of the community, information should be gained on the problem and the context in which it occurs.

To become acquainted with the real dynamics on farms a workshop was held which all parties involved attended. Certain NGOs, all the stakeholders involved in agriculture and all the researchers from various disciplines participated in this workshop. Important issues arose from the workshop, such as the problem of security on farms, general poverty and the migration of farm workers to and from farms (Protocol of the FLAGH study, 2001:2).

The workshop helped to familiarise the researchers with the situation on farms, with what could be expected during the research and with the practical planning of the project. Researchers were thus empowered to cultivate relationships with the members of the community in order to acquire an actual sense of the problem. The strengthening of relationships with the legitimate community leaders to gain entry into the community was of major importance. A collective sense of clarity regarding the exact nature of the problem could then be developed. Issues such as poverty, joblessness, employability, work shyness, income patterns, family relationships and political control should all be investigated in depth. All roleplayers then collectively discussed the extent of the proposed project.

After all the endeavours to delineate the real problems on farms, the entire team could collectively plan the project and decide on what should be done. As far as social work specifically was concerned, a number of psycho-social problems were delineated for study in this project. The researcher specifically decided to present a programme on ageing, advanced age and future perspectives.

When working in a research team consisting of various disciplines and individual researchers, it is of the utmost importance that everyone should have respect for the others' endeavours and should all realise that the various programmes have their own time limits. On the other hand, the various researchers had to plan together in order to stick to the completion date for the total project. With this realisation, the researcher had to plan his own programme, the time limits involved in the completion of the study as well as the tempo at which the community can move towards attaining their goals.

\section{Aim and objectives}

As soon as comfortable relationships are established, there is time to attend to the aims and objectives of the various disciplines participating in the study. It is, however, important to keep the policy guidelines of the central government in mind. In most cases the aims and objectives of the various groups will differ from each other seeing that every profession and professional has a distinctive agenda. The co-ordinator of the project had the unenviable task of integrating the various groups' aims and objectives as far as possible and accommodating each and every 
interest group in the project. From all the various agendas the co-ordinator had to formulate the final aims and objectives of the project.

The objectives for this project were to undertake a needs assessment and to develop, implement and evaluate possible programmes to enhance positive ageing, advanced age and a sense of the future perspectives of farm dwellers in the North-West province of South Africa and to enhance continuous interventions driven by students and community members. For the purpose of this article only the first two objectives are considered, namely the needs assessment and developing the intervention programme.

\section{Negotiation}

Discussion of the community's views on the research and the proposed outcomes should take place on a provisional and periodic basis throughout the study. This challenges the researcher to maintain the balance between the individual's and the group's agendas. In PAR projects it can be a problem to sustain the dedication of everybody who participates in the project, seeing that a variety of people are involved simultaneously. It is important that all involved in the project agree to a large extent on the nature of the project and maintain respect for each other's rights and the data-gathering procedures decided upon. This process entails negotiation and synergism, seeing that new perspectives do not necessarily overturn those that have become established, but rather elaborate on them.

In the atmosphere of shared control and support all role-players were encouraged to participate actively in the process. The researcher had to make sure that the so-called representatives of the community were the real representatives of all sectors and interest groups of the community and that all aspects of the identified problem get the necessary representation. Negotiation took place between the researcher and the democratically elected representatives of the community. Together all aspects of the problem were delineated in order to recommend relevant strategies for change.

Group dynamics play an important part in the PAR model. The focus was on everyone's correct and appropriate participation in order that nobody dominates and that all have equal opportunities to be involved in the total process. Group dynamics will to a large degree determine the success or failure of the project. The researcher must be willing to learn from and with others and to be sensitive, adaptable, patient, empathic and flexible. The capacity to evaluate the process critically from time to time and to make necessary adaptations remains important in any PAR project. The inputs should under all circumstances come from the community and not only from the researcher. The community has to take full ownership of the total process.

In this project negotiation took place by way of discussing the pros and cons of the project with the community leaders and later on with the community as such. Everybody's interests were taken into consideration as far as possible, provided that they did not hamper the group's agenda. The project leader had to exercise constraint on many occasions not to give his opinion on matters that he considered did not enhance the project. At all times the participants' interests were taken to heart and everything was done in order to facilitate the participation of all involved. The project leader did everything in his power to be flexible, sensitive and empathic to the needs and opinions of participants in order to gain everyone's full cooperation. 


\section{Planning}

The demands made on time and energy are highly unpredictable and will almost always exceed the original time schedule. Without flexibility, participation in the project will be difficult and empowerment of the community will not take place. The individual viewpoints of participants were integrated into the larger context of the total situation. At this time the researcher had a fair to good knowledge of the inherent strengths, weaknesses and skills of the community. The research questions were refined in order that everyone involved in the study could know exactly what was expected of them and what they could contribute towards data gathering and analysis. To gain consensus would probably take too much time to be productive, so the researcher settled for a majority vote. A decision was also made on what should be evaluated and on how this should be done.

All groups were prepared to solve the problem and to achieve the aim of the project. It was precisely determined what information would be necessary to delineate the problem and how the data could best be gathered. The entire team worked together to delineate the total project into manageable tasks and share the responsibility for each of these tasks amongst the participants.

\section{Implementation (needs assessment)}

PAR strives towards a holistic approach with the intended change in mind, which is not possible in traditional research. Obtaining the viewpoints of the disadvantaged community, the creation of mechanisms to ensure a critical view of the social reality and the mobilisation of human potential and support to solve the problem are important factors in this model.

The actual needs assessment took place at this stage and the focus was on the precise context of the limitations of the community. The survey technique - specifically the personal interview was implemented to gather the data (Babbie \& Mouton, 2001:251-254; Patton, 2002:341-348; Rubin \& Babbie, 2001:381-383; Wolcott, 2001:88-92). In this manner the needs and support of the community were systematically assessed. All the previous actions could be seen as the pilot study for this project. The questionnaire was pilot tested on three participants. This gave direction to the study and also enhanced the researcher's knowledge of the total situation. The whole population (McBurney, 2001:381-382) of older persons on these particular farms was interviewed, a total number of 42 respondents.

\section{Analysis of the data}

After completion of the needs assessment, the data were analysed. The data were categorised into certain themes in order to enhance evaluation of the data. The main themes that came to the fore are various relationships, healthy lifestyles, the issue of death, dying, bereavement and reminiscing, options for accommodation after retirement and some practical issues such as place of burial and transport.

\section{Evaluation}

The evaluation of data was done in order to recommend certain actions to be undertaken. Proper evaluation is also important for writing a report that can be viewed by all interested parties. Only when the data are written up in a report, can proper planning for implementation be undertaken. Evaluation should always be an integral part of the total process, including the degree to which the aims and objectives are reached, the level of skills attained and empowerment that took place in the community, as well as the advantages that participation 
holds for the community. After careful consideration of all the topics that came to the fore during the needs assessment, a proper evaluation was made of all the findings. It became clear that a programme covering all these topics should be presented to the older people living on these farms.

\section{Report writing}

Having completed the evaluation of the data, the findings were written up in a research report. A PAR research report should consist of the following sections: background information, problem statement, research questions, aim, objectives, literature study, research methodology, a discussion of the role-players, the processing and report writing on the data, the findings, conclusions and recommendations. The data from the needs assessment were written up in another article: "The perceptions and needs of farm dwellers on ageing, advanced age and future perspectives" (to be published). This particular article consists of background information to the study (including the problem statement), the objective of the study, the research methodology, the empirical findings, conclusions and recommendations for further study. A literature control was done of all the empirical data and was discussed under empirical findings in order to integrate the theory and practice related to the topic.

\section{The execution of the proposed action (the programme)}

The development of the programme took priority during this stage. The programme for this endeavour will be developed from the findings of the needs assessment and the researcher will take special care to ensure that the programme will be based on the actual needs of the participants. The programme will also be committed to a broad ecological view of human growth and change, with special attention to a strengths perspective (Lewis, 1996:100). It was evident from the findings that the presentation of the programme should be an empowering experience promoting self-reliance among the farm dwellers. From the findings of the needs assessment and literature on the topic (Morrow-Howell, 1992:395-404), the following themes came to the fore and will be incorporated into the programme:

- Relationships, especially relationships with children, grandchildren and spouses. (Probably a session will be conducted on each of the three kinds of relationships mentioned.);

- $\quad$ Social support, functioning, coping styles and care of older persons;

- A healthy physical lifestyle, covering aspects such as eating habits, alcohol misuse, smoking and exercise;

- A healthy emotional lifestyle, covering aspects such as the importance of positive thoughts, striving for happiness, and coping with sadness, sorrow, anxiety and fear;

- $\quad$ Death, dying, bereavement and reminiscing;

- The various options for accommodation after retirement, for instance, old age homes.

- $\quad$ Certain practical issues, such as the place of burial, funeral policies, finance and transport.

The programme will be presented by way of social group work in more or less 12 weekly sessions that will take place in the best possible venue available. The detailed content and the evaluation of the programme will be reported on in the: "An empowering psycho-social programme for ageing farm dwellers" (to be published) with the aim of empowering 
respondents and encouraging them to become self-reliant in order to take charge of their own life circumstances.

\section{- Evaluation of the outcomes}

Once the programme has been developed and presented to the target group, the results of the programme will have to be evaluated and presented in written form. The programme will be evaluated by way of a "before and after" measurement of all the members. The Perspective and Walmyr Assessment Scales will be utilised, specifically the Generalised Contentment Scale (GCS) and the Index of Self-esteem (ISE) (Bloom, Fischer \& Orme, 1999:220-221) as standardised measuring instruments. Additionally a self-developed measuring scale, consisting of both qualitative and quantitative items comprising open and closed ended questions, will be used.

It is likely that, after the evaluation of the initial programme, certain changes will have to be made to the programme. There might be aspects of the preliminary programme that will be positively evaluated and will most probably be kept unchanged for the final programme, while some aspects of the programme might be negatively evaluated and will most probably need adaptation or be left out in the final programme. This total re-evaluation process represents another phase of the research in order to keep the most appropriate items for the final programme. In this way action and research interplay with one another as alternative processes in the solution of the problem. The action part of the process keeps the research relevant, initiates further research and implements the research findings, while the research part of the process guides the action and evaluation.

\section{SUMMARY}

In the Participatory Action Research Model the emphasis is on the involvement of all roleplayers as far as possible, meaning the majority of members and the researcher. The PAR model focuses on social justice and equality in disadvantaged communities of people who are powerless and disadvantaged. The community work and the research processes are used in a complementary fashion in this model and the so-called barriers between them become blurred. Concepts such as community, mobilisation, capacity building, empowerment, human wellness, self-reliance and community participation play a major role in the PAR model. The Participatory Action Research Model has potential for all the helping professions in future in order to empower communities with knowledge and skills so that these communities can delineate and solve their own problems.

\section{BIBLIOGRAPHY}

ALVAREZ, A.R. \& GUTIÉRREZ, L.M. 2001. Choosing to do Participatory Research: an example and issues of fit to consider. Journal of Community Practice, 9(1):1-20.

BABBIE, E. 2001. The practice of social research. London: Wadsworth.

BABBIE, E. \& MOUTON, J. 2001. The practice of social research. Cape Town: Oxford University Press.

BARKER, R.L. 1995. The Social Work Dictionary. Washington: NASW Press.

BERESFORD, P. \& EVANS, C. 1999. Research and empowerment. British Journal of Social Work, 29(5):671-677. 
BLESS, C. \& HIGSON-SMITH, C. 2000. Fundamentals of social research methods: An African perspective. Lansdowne: Juta Education.

BLOOM, M.; FISCHER, J. \& ORME, J.G. 1999. Evaluating practice: Guidelines for the accountable professional. London: Allyn and Bacon.

BOERSEMA, N. \& MACONACHIE, M. 1995. Between practice and paradigm: An exploratory study in participatory evaluation. Pretoria: Human Sciences Research Council.

BURKEY, S. 1998. People first: A guide to self-reliant, participatory rural development. London: ZED Books.

COLLINS, K. 1999. Participatory research: a primer. Johannesburg: Prentice-Hall.

DEPOY, E.; HARTMAN, A. \& HASLETT, D. 1999. Critical action research: a model for social work knowing. Social Work, 44(6):560-569.

GIBBS, A. 2001. The changing nature and context of social work research. The British Journal of Social Work, 31(5):687-704.

HAKIM, C. 2000. Research design: Successful designs for social and economic research. London: Routledge.

HEALY, K. 2001. Participatory action research and social work: a critical appraisal. International Social Work, 44(1):93-105.

HOLMAN, B. 1987. Research from the underside. The British Journal of Social Work, 17(6):669-683.

KAHN, S. 1994. How people get power. Washington: NASW Press.

KONDRAT, M.E. \& JULIÁ, M. 1997. Participatory action research: self-reliant research strategies for human social development. Social Development Issues, 19(1):32-49.

LEWIS, J.S. 1996. Sense of coherence and the strengths perspective with older persons. Journal of Gerontological Social Work, 26(3/4):99-111.

MARAIS, H.C.; MUTHIEN, Y.; JANSEN VAN RENSBURG, N.S.; MAAGA, M.P.; DE WET, G.F. \& COETZEE, C.J. 2001. Sustainable social development: Critical issues. Pretoria: Network Publishers.

McBURNEY, D.H. 2001. Research methods. London: Wadsworth Thomson Learning.

McNICOLL, P. 1999. Issues in teaching participatory action research. Journal of Social Work Education, 35(1):51-62.

MORROW-HOWELL, N. 1992. Multidimensional assessment of the elderly client. Families in Society, 73(7):395-407.

MORSE, J.M. 1997. Completing a qualitative project: Details and dialogue. London: SAGE Publications.

NANTEL, G. 2001. Community Based Nutrition Programming (CBNP). Lecture delivered by Dr G Nantel, senior officer, Planning, Assessment and Evaluation Service: Food and Nutrition Division of the Food and Agricultural Organization (FAO) of the United Nations on 29 March 2001 at the PU for CHE, Potchefstroom. 
NEUMAN, W.L. 2000. Social research methods: Qualitative and quantitative approaches. London: Allyn and Bacon.

PATTON, M.Q. 2002. Qualitative research and evaluation methods. London: Sage Publications.

POTTIER, J. 1993. Practising development: Social science perspectives. London: Routledge.

Protocol of the FLAGH study, 2001, pp. 1-24.

RAHMAN, A. 1993. People's self-development: Perspectives on participatory action research. London: ZED Books.

ROTHMAN, J.; ERLICH, J.L. \& TROPMAN, J.E. 1995. Strategies of community intervention: macro practice. Itasca: F.E. Peacock Publishers.

RUBIN, A. \& BABBIE, E. 2001. Research methods for social work. London: Wadsworth Thomson Learning.

SCHURINK, E.M. 1998. Participatory action research as a tool for sustainable social development and reconstruction. In: DE VOS, A.S. (ed) Research at grass roots: A primer for the caring professions. Pretoria: J.L. van Schaik, 405-418.

STRYDOM, H. 2001. Deelnemende aksie-navorsing as model vir benutting deur gesondheidswetenskaplikes. Social Work/Maatskaplike Werk, 37(4):379-392.

VAN ROOYEN, C. 1998. Democratising social work research. In: GRAY, M. (ed) Developmental social work in South Africa: Theory and practice. Johannesburg: David Philip Publishers.

VORSTER, H.H.; WISSING, M.P.; VENTER, C.S.; KRUGER, H.S.; KRUGER, A.; DE RIDDER, J.H.; VELDMAN, S.J. \& STEYN, H.S. 2000. The impact of urbanization of physical, physiological and mental health of Africans in the North West province of South Africa: The THUSA study. South African Journal of Science, 96:505-513.

WHITE PAPER ON SOCIAL WELFARE. 1997. Pretoria: Department of Welfare.

WHYTE, W.F.; GREENWOOD, D.J. \& LAZES, P. 1989. Participatory action research: through practice to science in social research. American Behavioral Scientist, 32(5):513-551.

WOLCOTT, H.F. 2001. Writing up qualitative research. London: Sage Publications.

YEGIDIS, B.L. \& WEINBACH, R.W. 1996. Research methods for social workers. London: Allyn and Bacon. 